\title{
Role of Television in Child Development
}

\section{B.P.Mahesh Chandra Guru ${ }^{1 *}$, Aabid $\mathrm{Nabi}^{2}$ and Raja Raslana ${ }^{2}$}

${ }^{1}$ Professor and Chairman, DOS in Communication and Journalism, University of Mysore, Manasagangotri, Mysore-06, India ${ }^{2}$ University of Mysore, India

\begin{abstract}
Child development has been considered as a priority sector by the policy makers in India and other countries. A new generation of children has grown up with television exposure in modern society. The impact of television on the personality of the children needs to be examined scientifically and systematically in modern society. Children spend a sizeable chunk of their time on watching television programmes. Children are greatly influenced by television programmes. Parents and caregivers have a great responsibility of providing right kind of orientation to the children regarding the cultivation of television habits, choice of television programmes and impact of television on children. Communications media including television have a great Corporate Social Responsibility in promoting healthy personality in children. Practically all developing countries have accepted communication as an integral part of national development planning. The role of television in child development is also subjected to scientific investigation all over the world. Investigations dealing exclusively with the impact of television on child development are scanty as seen through the paucity of literature. Most behavioral scientists have observed that too much of television viewing by the children would result in the exclusion of other healthy activities.
\end{abstract}

\section{Introduction}

Child development has been considered as a priority sector by the policy makers in India and other countries. The founding fathers of our Constitution have provided series of specific safeguards for the human resources development in the country. The Directive Principles of State Policy have laid emphasis on child development. There is a phenomenal growth of mass media including television all over the globe. The role of television as a medium of communication and development is subjected to scientific research in India and elsewhere. A new generation of children has grown up with television exposure in modern society. The impact of television on the personality of the children needs to be examined scientifically and systematically in developing countries like India and Iran. The present paper deals with the role of television in the process of child development.

\section{Children and media}

Children constitute more than $1 / 3$ of the world's population and almost half of the world's population is under the age of 25 according to be latest statistics. In the age of globalization, media institutions and services are controlled by the market forces. The media institution are also spreading the global culture in the age of technological a revolution. Critically speaking, media institutions have not lived up to the expectations of people from the point of view of their contributions for child development. Becker have pointed out that the strength of world capitalism is directly related to its ability to sell not merely goods, but also ideas and more generally ideologies that sustain the levels of consumption of people. In reality, the growth of consumerism among the children and youth is the direct consequence of the growth of transnational mass media dominated by market forces according to Sheykhi.

The Centre for the study of Children, Youth and Media Institute of Education reports that a growing proportion of the trade in global media markets is now dominated by a small number of vertically integrated, multi-media corporations which national governments seem powerless to resists. The multi-national corporations have now conceived international media markets which provide the benefit of the global consumers. The gap between global and local media perspectives is becoming thinner in the age of globalization of media and economy. Scholars have noted that children are not passive recipients of transnational media output. The relationship between media and children is subjected to serious media debates and investigations all over the globe.

Buckingham [1] observes: "Technological developments and global economic deregulation within the media industries have resulted in a significant proliferation of channels and outlets in recent years. Children have been a key target market for these new services and most cable/satellite packages offer at least six dedicated children's channels. Children have also become an increasingly significant target market for media companies. At the same time, the child audience is increasingly merging with the youth audience. The children have always preferred to watch programmes aimed at the general audience, rather than children's programmes specifically".

Children are actively associated with the media services as consumers but they want the media institutions to provide the goods and services from their everyday life point of view. Experience reveals that children also employ media stories to reflect their own experiences. "Media institutions have also taken note of the aspirations of the children and started the delivery of services in order to develop media-literate children since it is necessary to invest in media-literate educators and parents", according to Gotz et al. [2].

Children are no more silent spectators in this age of competitive media services. Scholars and advocates of child rights have strongly argued in favor of $-\mathrm{a}$ ) recognition of children's right to have a voice in the media, b) adoption of media programming standards based on a clear understanding of children's rights and c) use of the code

*Corresponding author: B.P.Mahesh Chandra Guru, Professor and Chairman DOS in Communication and Journalism, University of Mysore, Manasagangotri, Mysore-06, India, E-mail: ademike2000@yahoo.com

Received February 14, 2013; Accepted April 23, 2013; Published April 30, 2013

Citation: Mahesh Chandra Guru BP, Nabi A, Raslana R (2013) Role of Television in Child Development. J Mass Communicat Journalism 3: 153. doi:10.4172/21657912.1000153

Copyright: (C) 2013 Mahesh Chandra Guru BP, et al. This is an open-access article distributed under the terms of the Creative Commons Attribution License, which permits unrestricted use, distribution, and reproduction in any medium, provided the original author and source are credited. 
as a tool that will enable monitoring of different forms of violations of children's rights in the media. Serious discussions are held across the globe regarding the media code of conduct to realize children's rights which is spearheaded by the Concerned for Working Children. There is also growing realization among the children over the absence of media activism in relation to child rights protection and personality development of children.

\section{Television as a medium of communication}

Television was indeed, one of the greatest inventions of $20^{\text {th }}$ century. John Logie Baird gets the credit for inventing the $1^{\text {st }}$ mechanical working television system in 1926. Vladimir Kosma Zworykin demonstrated a system of Television with a cathoderay tube called 'kinescope' which is the basis of modern television. Television is basically an audio - visual medium of communication which makes optimum use of sight and sound. This unique medium communicates information, education, advertisement, entertainment, publicity, propaganda and other services to the mankind by combining the elements of sound, picture, motion, color and drama. It simultaneously appeals to one's sense.

The eye is one of the most powerful sensory organs and two thirds of learning comes through the sense of sight much more than what people learn through the sense of sound. Audio-visual information lasts long in one's memory. The presence of color enables one to show things in natural colors enhancing the level of communications. The motion gives one more dynamism to the process of communication. The other chief element is drama that is interwoven in the presentation. Thus, the presence of these rich characteristics of theatre in television makes the communication process more effective and helps the viewers in the perception of information.

The live nature of television allows it to transmit visuals and information almost instantly. This capacity of television makes it ideal for transmitting live visuals of news and various events. A large number of audiences who cannot read or right can watch television and access the information shown on television. As a medium of communication, television also as a very wide output, range and reach. By nature, television is generally identified as a transitory medium of communication. It is different from other media of communication. It combines compelling visuals with the personal immediacy of radio. This audio visual character gives television a great power in conveying realism which keeps the viewers emotionally involved with the programme. It allows the audiences to witness various events which take place around the world. The new media enable the audiences to participate in various events by posting their comments on websites.

Television as a mass medium has tremendous influence on modern society. No medium has ever dominated people's lives as television did. Today television has replaced the film as a dream machine to emerge as the most popular and powerful medium of mass communication. Television is mainly responsible for the rapid shrinking of the world-a world without boundaries. It is obvious that television plays a dominant role in modern society. It is widely understood that television has both positive and negative impact on people.

Today people spend most time watching variety of television programmes both domestic and foreign. It is very well said that television is the heavy weight of all mass media. Nicholas Johnson observes: "Television is one of the most powerful forces man has ever unleashed upon himself". It denotes the importance television has assumed in our lives and the dramatic changes it has brought about in our modern society.
The highly advanced TV cameras can also take breath taking pictures or space and the deep sea in close proximity. The medium makes abundant use of close-up shots. Television is also referred to as 'the medium of close-ups'. New communication technologies like computers and tele-communications have the characteristics of personal communication. Television has also become an interactive medium which provides the benefit of live-show, phone-in programmes and video conferences. New technology has also paved the way to easily access the Internet on television itself instead of a conventional computer monitor. Thus, television has become a multifaceted medium compatible with new communication technologies.

According to the latest statistics compiled by the contemporary television industry generates about 40,000 dollars in the world. The prominent companies include-Sony Corporation, Vivendi, Walt Disney Company, Comcast, News Corporation, Time Warner Inc, The Direct TV Group, Bertelsmann AG, Time Warner Cable, Cox Enterprises, CBS Corporation, Viacom Inc, Lagarde're, ARD, Pearson, $\mathrm{BBC}$ and so on. These organizations generate more than 10,000 dollars individually. In terms of distribution of worldwide television revenue by region, North America (38\%), Europe (31\%), Asia Pacific (21\%), Latin America (8\%) and Middle East and Africa (2\%) occupy important positions. In terms of television households worldwide by region, Asia Pacific (52\%), Europe (23\%), Latin America (10\%), North America (10\%) and Middle East (5\%), occupy dominant positions. There are also digital and non-digital television subscribers all over the world. Television also generates maximum advertising revenue all over the globe one compared to other media of communication

\section{Research on children and television}

Children spend a sizeable chunk of their time on watching television programmes. Children are greatly influenced by television programmes. Parents and caregivers have a great responsibility of providing right kind of orientation to the children regarding the cultivation of television habits, choice of television programmes and impact of television on children. Most behavioral scientists have observed that too much of television viewing by the children would result in the exclusion of other healthy activities. Children also find it very difficult to understand the basic difference between fact and fantasy.

The children are very much attracted by the television which is known for glamour. Experience reveals that the age and stage of child development makes a big difference. It is also true that repeated experiences can become patterns that begin in childhood and extend into adolescence. Children are not born with prejudices but they learn them from the people around them. Television can introduce children to stories, traditions and songs. The kinds of messages children get from television will affect how they think of others. As early as six months of age, infants notice skin differences and by their second year, they start to question how people are alike and different. Between two and a half and three and a half years, children begin to absorb the messages from parents, neighbors, friends, books and television about people from other races.

The first two years of childhood are so important in the cognitive growth and development of children. Children under six years usually face some difficulty working out the difference between fantasy and reality on television. Children from six to nine years are bound to have some difficulty working out the difference between fantasy and reality, especially if it looks like real life. They tend to admire and want to be like the hero or heroine. Older primary school age children are likely to 
be disturbed by material that is based on fact as it could mean it could happen to them. They are curious about the teenage world, sex and fashion and can be misled by the way boy-girl relationships are shown in the television screen. The children are affected by the television programmes in several ways according to empirical findings. Children need to understand and enjoy the mixture of differences in lifestyles and traditions that make up the society.

Television has the potential to generate both positive and negative effects, and many studies have looked at the impact of television on society, particularly on children and adolescents. The child's developmental level is a critical factor in determining whether the television and other media will have positive or negative effects. Television viewing frequently limits children's time for vital activities such as playing, reading, learning to talk, spending time with peers and family, storytelling, participating in regular exercise, and developing other necessary physical, mental and social skills according to several studies.

Television has a strong influence in consumers including the children. But this influence can be understood within a larger and more complex framework of lifestyles and social relations of individuals and groups. Television is also responsible for the construction of meanings and the possibility of interpreting what children watch or do not watch and television can influence the way children understand what they watch over television and meanings they obtain from the contents. The research carried out in different parts of the world revealed the importance of the direct interaction between television and children. Scholars have also examined the television experiences of children.

In the beginning, most of the research on media effects was done in the West since the spread of media was rapid and effect of media and society was strong over there. In the first stage, the researchers concentrated on the theoretical aspects of media management and delivery system. In the second stage the researcher carried out investigations on the effect of print media, film and radio during 1940s since the presence of television was not felt by many in the world. The third phase witnessed the new phase of research which laid emphasis on the effect of television on children. Himmelweit, Oppenheim and Vince [3] and Schramm, Lyle and Parker [4] were the prominent researchers who studied the role of television in the lives of the children. The researchers concentrated mainly on the television viewing habits of children rather than the impact of television on children. The initial faith attached to the inhibition hypothesis waned, however, when early studies comparing the reading skills of viewers with those of nonviewers failed to confirm the inhibition hypothesis.

In the decade of 1970s, the United States witnessed unprecedented violence which was depicted in the television programmes. This situation prompted the policy makers in America to appoint a Scientific Advisory Committee on Television and Social Behavior headed by Jesse Steinfield [5]. He reports: "The experimental findings are weak and are not wholly consistent from one study to another. Nevertheless, they provide the suggestive evidence in favour of the interpretation that viewing violence on $\mathrm{TV}$ is conducive to an increase in aggressive behavior, although, it must be emphasized that the causal sequence is very likely applicable only to some children who are predisposed in this direction and TV is only one of the many factors which in time may precede aggressive behavior".

In the 1970s, belief in the inhibition hypothesis was restored by the publication of two types of evidence exciting the suspicion that the reading skills of America's youth had changed for the worse. First, in a number of reviews of test-score trends published in the middle to the end of the 1970s, the conclusion was reached that children's reading skills had been declining dramatically since the mid- 1960s. Second, several studies on the functional literacy of (young) adults were published, most of which conveyed the impression that a great many Americans were insufficiently equipped with the writing and reading skills necessary to use and understand the printed material one. Spurred by the revived public debate, quite a few researchers have carried out studies, especially since the mid-1970s regarding the role of television in the lives of children. Researchers also examined the role played by television in the child's development of academic and social skills.

The decade of 1990s witnessed series of organized and scientific investigations on the effects of television on children's personality and progress. The researchers carried out several experimental studies which revealed that television contents did not produce the same response from all the television viewers. They also observed the relationship between the stimulus and the response of the children to the television programmes. The past studies identified several intervening factors such as personality factors, family environment, cultural factors, economic factors and social factors which had a considerable impact on the television viewing habits of children in general and effects of television on children in particular. Some studies also pointed out that justified or rewarded violence had more impact on children who viewed the television programmes. A review of the research on children and television carried out in this decade also revealed that largest proportion of 'effects' studies focused on aggression specifically.

Norma Pecora [6] observes: "The global nature of children's television must continue to be considered in the future in terms of the economics of the industry, comparative studies technological availability and media use, and the cultural and social implications of non indigenous messages and representation. Questions of media violence have been the central issue in the debate on children's relationship to the media.

The dawn of $21^{\text {st }}$ century witnessed multi-dimensional and multi-directional investigations which dealt with the impact of television on children. Television became a well established medium of communication which attracted the attention of audiences including children. The market forces broadcast television programmes which affected the children adversely in the age of globalization of media. Several scholars primarily focused on the attitude of children towards television viewing, attitude of parents towards television viewing, parental mediation in children's television viewing, impact of television advertisements on children and other aspects.

There are a plethora of television channels which offer greater choice and quality (both positive and negative) of programming to the mankind. Television is now an interactive experience with children being able to interact digitally as they watch and continue the experience online. It is clear that Television viewing, like any life experience, needs to be managed and monitored in the very young with supervision decreasing as the children learn to appropriately manage their own viewing behaviour, critically evaluate what they view and discuss any issues or concerns that come out of what they have viewed. Contemporary research has highlighted that for many families, television is an essential part of modern culture and it needs to be monitored and managed with increasing parental confidence given advances in technology. It is important that parents are supported and feel empowered-via their own management choices and their use of 
the available technologies which have given the benefit of connectivity to the mankind.

\section{Role of television in child development}

Child development is not a uni-dimensional aspect of human development. There are several characteristics which depict the state of child development. Prominent among them include speed and pattern of development, mechanisms of developmental change, population differences, individual differences, motor development, cognitive development, emotional development, social development, language development and so on. The scholars have brought all these aspect of child development under 'developmental psychology' which refers to development of human beings throughout their lifespan. Child development broadly constitutes the overall development of children.

The role of television in child development is widely debated all over the world since the decade of 1950s. Several commissions and individuals have examined the effects of television programmes and commercials on particular segments of global population, specifically children. A substantial amount of research has been carried out in order to develop a considerable body of knowledge concerning the role of television in child development. Mc Luhan observes: "we need to know more about what elements in the television programmes influence children's personality and what preventive measures are effective in molding the personality of children in future since television cultivates forms of thought that are fundamentally different from those used in processing print or some other media".

Van Evra conducted an intensive and extensive review of major studies about television and child development by both communication scholars and developmental child psychologists. She also pointed out that moderate viewing of television programmes would help develop the communication skills of children from disadvantaged background. She further pointed out that technological innovations such as VCRs, cable, home videos, video games, computers, etc. had new influences in the lives of children. Scholars have also recognized that television enabled the children to learn certain pro-social behaviors. The uses and gratifications theory also pointed out that heavy television viewing resulted in a more serious effort to derive information and knowledge from what was viewed by the audiences.

Edgar and Edgar observe: "television programmes can stimulate a child's imagination and open up the infinite opportunities that life presents. Like good books, good television programmes can extend children's understanding of their world. Children will watch good programs repeatedly and keep watching them as they grow older, learning different things each time because they can engage with quality in increasingly sophisticated. Good children's television comprises programs made especially for children that reflect the complexity of the emotional changes within the age group and honestly deal with conflicts that such diversity demonstrates. Technology makes it possible to design programs that are not only appropriate to a particular age group, but also to different developmental level within that age group. Good programming can teach the children valuable lessons about living in community".

Television has also become a prominent educational medium since it uses a language or a symbol system which differs in many ways from other communications media. It conveys more experiential meanings and provides useful educational packages to the children. The success of Sesame Street is a result of a combination of a well functioning technology of transmission and a symbol system which represence otherwise mundane contents in a highly appealing manner. A good deal of research effort has been directed upon the role of television in child development. Piaget identifies four major stages of child development namely-sensory motor (0-2 years), pre-operational (2-6years), concrete operation (7-13 years) and formal operations (14 years on). The television programmes have the capacity to facilitate cognitive development in children if they are produced and broadcast in accordance with the specific needs of the children. Studies have revealed that children learn certain behavioral patterns through television programmes which are carefully planned, designed and broadcast to improve cognitive development of children. Investigations have also a revealed that television programmes have produced positive and negative effects on children.

Heather et al. [7] comment: "although research clearly demonstrates that well-designed, age-appropriate, educational television can be beneficial to children of preschool age, studies on infants and toddlers suggest that these young children may better understand and learn from real-life experiences than they do from video. Early exposure to age appropriate programmes designed around an educational curriculum is associated with cognitive and academic enhancement, whereas exposure to pure entertainment, and violent content in particular, is associated with poorer cognitive development and lower academic achievement. Research on children's television viewing can inform guidelines for producers of children's media to enhance learning".

Researchers have provided information on the role of television in the development of cognitive skills of children who become active media users after 3 years. Aletha Huston and John Wright [8] proposed a theory of attention to television which stated that the features of television that drive children's attention may change as a child ages. The children were less influenced by perceptual silence and were able to pay greater attention to informative features such as dialogue and narrative.

Daniel Anderon argued that television viewing was based on active cognition of children. According to them, the preschool children paid more attention to children's programmes than to commercials. Children also learnt strategies for watching television by using their knowledge of formal features to guide attention according to Campbell. Kremar have found that children younger than two learned vocabulary better than real-life experiences than from equivalent video presentations. Crawley et al. [9] found that television as a medium does not have an indiscriminate negative effect on attentional skills but can teach specific attentional skills and strategies if they are properly designed and presented. Studies have also revealed that educational television programmes which are designed around a curriculum with a specific goal to communicate academic or social skills teach their intended lessons to the children.

Zimmerman and Christakis [10] noted that concern over television exposure before age two was echoed in research on cognitive development of children. The television programmes also have the capacity to demonstrate immediate and potentially long-lasting effects of problem-solving skills especially for regular viewers of the programme among the children, according to Crawley and others [9]. Ball and Bogatz [11] had pointed out that certain television programme Sesame Street designed for young children focus on variety of academic and social skills to help prepare children for entering school.

Din and Calao [12] noted that professionally produced, curriculum based Internet websites for preschoolers enabled the children to learn academic and social skills which had long-lasting effects. Studies have 
also established a well defined association between television exposure and child development across the globe. Vandewater et al. [13] noticed that television viewing did not displace educationally valuable activities of children, except in the case of children and youth with extraordinarily high television exposure.

A meta analysis of twenty-three studies carried out by Williams et al. [14] suggested that moderate television viewing (one or two hours a day), was positively associated with academic achievement but higher rates of television viewing were associated with decreasing academic achievement children. Studies have also underlined the importance of early exposure to specifically educational television programming which enhanced the academic achievement of children. Early exposure to educational programming was also positively linked with a host of other factors such as leisure time reading involvement in extracurricular activities according to Anderson et al. [7].

Educational programmes are positively associated with overall measures of achievement and with potentially long-lasting effects. Harris and Williams [15] reported a positive association between achievement and computer and Internet use at home. Fisch [16] has suggested that producers integrate narrative and educational contents as much as possible in order to maximize the cognitive resources available to children. Fisch argues that transfer of learning and analogical reasoning in children can be maximized not only by repeating the educational messages in the course of television episode but also by varying the contexts surrounding each presentation. He further suggests that presenting the same lesson, such as specific problem-solving strategy, several time using different types of examples can increase the flexibility of a child's mental representation of that strategy.

Friedrich and Stein [17] have also stated that parent coviewing and mediation would enhance the effectiveness of educational programming by drawing attention to the most important aspects of the programme and by extending lessons presented in the programme. According to them, coviewing with a parent or other adult may increase a child's learning from educational television, particularly when the coviewer actively mediates by explicitly drawing attention to the problem and by asking and answering questions. Learning from educational software can also be enhanced when an adult provides feedback or extends lessons to the children who need free interactive experience according to Haugland [18]. Studies have emphasized the role of television in the cognitive skill development and academic achievement of children who are enabled to enjoy the benefit of early exposure to television. Television has powerful influence on the lives of contemporary children who are the future builders of nation.

\section{Summary}

Child development assumes great significance in India, Iran and other developing nations. Childhood is considered as a very crucial stage of human development by the development psychologists. In fact, childhood is diminishing due to several social, educational, economic, political, psychological, cultural and environmental factors and forces which have disturbed the childhood. There are several stakeholders who are responsible for promoting healthy personality in children. After independence, various child development measures have been devised and implemented in India and Iran in order to facilitate healthy development of children who are the future nation builders. Communications media including television have a great Corporate Social Responsibility in promoting healthy personality in children. Practically all developing countries including India and Iran have accepted communication as an integral part of national development planning. The role of television in child development is also subjected to scientific investigation all over the world. Investigations dealing exclusively with the impact of television on child development in India and Iran are scanty as seen through the paucity of literature. The effects of television viewing on the growth and development of children during middle and late childhood in India and other developing countries need to be examined in order to promote healthy personality of children.

\section{References}

1. Buckingham, David (2003) Children and media.

2. Gotz, Maya, Dafna L, Amy A, Hyesung M (2004) The role of media in children's make believe worlds

3. Himmelweit HT, Oppenheim AN, Vince P (1958) Television and the child an empirical study of the effects of television on the young, London: Oxford University Press.

4. Schramm W, Lyle J, Parker E (1961) Television in the lives of our children Stanford, CA: Stanford University Press.

5. Steinfield, Jesse (1972) Report of the Scientific Advisory Committee on Television and Social Behavior, US

6. Pecora, Norma, John P, Murray and Ellen Ann Wartella (2007) Children and television: fifty years of research, Mahwah, New Jersey and London : LEA

7. Heather L, Kirkorian, Ellen A, Wartella, Daniel RA (2008) Media and young children's learning. Spring 18: 39-61.

8. Huston, Wright (1983) Children's processing of television: the informative functions of formal features, In J.Bryant and D.R. Anderson (eds) Children's Understanding of Television: Research on Attention and Comprehension, Academic Press, New York.

9. Crawley AM (1999) Effects of repeated exposures to a single episode of the television programme Blue's Clues on the viewing behaviors and comprehensions of preschool children. Journal of Educational Psychology 91 630-637.

10. Zimmerman FJ, Christakis DA (2005) Children's television viewing and cognitive outcomes: a longitudinal analysis of national data. Arch Pediatric Adolescent Med 159: 619-625.

11. Ball S, Bogatz GA (1970) The first year of Sesame Street: an evaluation Princeton, N.J., Educational Testing Service.

12. Din FS, Calao J (2001) The effects of playing educational video games on kindergarten achievement. Child Study Journal 31: 95-102.

13. Vandewater AE, David SB, June HL (2006) Time well spent? relating television use to children's free-time activities. Pediatrics 117: 181-191.

14. Williams PA, Haestel EH, Haertel GD, Walberg HJ (1982) The impact of leisuretime television on school learning: A research synthesis. American Educational Research Journal 19: 19-50.

15. Harris, Jennifer L, John A, Bargh, Kelly DB (2009) Priming effects of television food advertising on eating behavior. Health Psychology 28: 404-413.

16. Fisch SM (2000) A capacity model of children's comprehension of educational content on television. Media Psychology 2: 63-91.

17. Friedrich LK, Stein AH (1975) Pro-social television and young children's behavior: the effect of verbal labeling and role playing training. Child Development 46: 27-38.

18. Haugland SW (1992) The effect of computer software on preschool children's developmental gains. Journal of Computing in Childhood Education 3: 15-30. 